\title{
Predicting Mammal Species Richness from Remotely Sensed Data at Dif- ferent Spatial Scales
}

\author{
Boniface Oluoch Oindo*
}

\author{
School of Environment and Earth Sciences, Maseno University, P.O. Box 333, Maseno, Kenya
}

\begin{abstract}
Spatial variability in species richness has been postulated to depend upon environmental factors such as climatic variability, Net primary productivity and habitat heterogeneity. The Advanced Very High Resolution Radiometer (AVHRR)-Normalized Difference Vegetation Index (NDVI) has been shown to be correlated with climatic variability, Net primary productivity and habitat heterogeneity. Moreover, Landsat Thematic Mapper (TM) derived habitat diversity indices have been used to reflect habitat heterogeneity. Interannually average NDVI and its variability (standard deviation and coefficient of variation) as well as Landsat Thematic Mapper derived habitat diversity index were correlated with mammal species richness at landscape scale. Species richness related unimodally to interannual average NDVI and positively to variability of NDVI and habitat diversity index. Conversely, at regional scale mammal species richness were correlated with interannually average NDVI and coefficient of variation of NDVI. Species richness related negatively to the latter and positively to interannually average NDVI. Though these relationships are indirect, they apparently operate through the green vegetation cover. Understanding such relationships can help in estimating changes in species richness in response to global climatic change.
\end{abstract}

Keywords: AVHRR-NDVI, habitat heterogeneity, landscape scale, landsat thematic mapper, mammal, net primary productivity, regional scale, species richness.

\section{INTRODUCTION}

Explanations for geographical variation of species richness have stimulated much discussion and numerous hypotheses have been advanced to account for species richness patterns $[1,2]$. Each hypothesis only successfully explains patterns of species richness in specific locations for certain taxonomic groups and at certain scales. Patterns of species richness at landscape and regional scales have been of continual interest to biogeographers and ecologists [3]. Species richness on these two spatial scales seem likely to be controlled by different factors. Regional species pools exist, the sizes of which probably depend on factors that act on coarse scales (e.g., climatic variability); landscape subsets seem likely to be derived from the regional pool by landscape processes such as habitat heterogeneity. This hypothesis suggests two separate questions: What factors determine the size of regional species pools, and what factors control the subsampling from the regional pool that establishes landscape pools?

The most popular biophysical factors hypothesized to affect species richness at regional scale are net primary productivity and climatic variability. Whereas habitat heterogeneity and net primary productivity are popularly used to predict species richness at landscape scale [4]. The productivity hypothesis predicts that when resources are abundant and reliable, species become more specialized, allowing more species per unit area. However, empirical evidence shows that higher productivity can be either negatively or positively

\footnotetext{
*Address correspondence to this author at the School of Environment and Earth Sciences, Maseno University, P.O. Box 333, Maseno, Kenya; Tel: +254-722677862; E-mail: booluoch@yahoo.com
}

correlated with species richness. In fact, in many systems a unimodal pattern is found, with highest species richness at intermediate levels of productivity; above the point of central tendency species richness decreases as productivity increases, while below the point of central tendency species richness increases as productivity increases [5]. A number of explanations of this apparent paradox have appeared [6], but no single theory has been accepted by ecologists.

In regional biodiversity studies, productivity is usually calculated from weather station records collected at scattered (and often biased) sampling points-these points are extrapolated in order to characterize productivity over a large region [7, 8]. Such climate-based models assume that the vegetation cover is 'natural', and ipso facto is under the control of climate [9]. However, at a landscape scale, vegetation productivity is also influenced by non-climatic factors including soil nutrient and structure, topography, disturbance and land use. Productivity and related variables have been mapped over large areas with remote sensing [4]. Thus, remote sensing has great potential as a source of information for mapping patterns of species richness over large areas [10, 11]. The Advanced Very High Resolution Radiometer derived Normalized Difference Vegetation Index (NDVI) has been related to net primary productivity (NPP) at coarse spatial scales [9]. Thus, mean maximum NDVI provide a more accurate index of ecosystem productivity compared with climate-based models, by virtue of being spatially explicit [12].

The heterogeneity of an area is strongly (positively) correlated with the number of species that are found in that particular area [13]. The heterogeneity hypothesis states that physically and biologically complex habitats furnish more niches that support richer assemblages of biological species 
compared with simple ecosystems [14]. Factors contributing to the environmental heterogeneity are the spatial or temporal variation in the physical, chemical or biological features of the environment that create different conditions (or niches) that species can preferentially exploit [15]. Hence, species diversity increases with niche or resource diversity because each species must occupy a distinct niche [4]. Researchers have examined the spatial configuration of habitat variables to predict species richness [4]. Landscape ecologists have derived or adapted indices of habitat heterogeneity from remotely sensed data products such as land cover or habitat maps [16]. By combining information about known habitat requirements of species with maps of landcover derived from satellite imagery, precise estimates of patterns of species richness are possible [17]. In their study [18], used Landsat TM derived habitat map to compute the ShannonWiener and Simpson's indices of diversity for the Maasai Mara ecosystem, Kenya. Areas with the highest habitat diversity were found to support higher numbers of herbivore species than areas with relatively less habitat diversity. However, some of these indices can be sensitive to spatial resolution and to the number of landcover classes, making generalizations of their relationships to species richness difficult [4]. Moreover, researchers have demonstrated that the within-region variability of NDVI values, for instance defined as the standard deviation of maximum NDVI relate to the heterogeneity of habitats, and consequently have a positive relationship with species richness $[19,20]$.

The climatic-stability hypothesis states that accumulation of species over a long time in places where environmental conditions remained stable and predictable causes high species diversity $[21,22]$. This is due to the fact that areas with predictable and stable climates may permit a more constant influx of resources and the evolution of greater specialization of niches [2]. By contrast, the exploitation of areas with unstable climate may require evolution of broad tolerances to deal with a wide range of environmental conditions [7]. This should lead to decrease in the number of species as the amplitude of periodic climatic fluctuations increases [2].

NDVI has been shown to be highly sensitive to rainfall anomalies such as drought [23], allowing NDVI to be used as a good proxy of interannual climate variability [24]. Therefore, the vegetation index time series give us a possibility to assess the climatic variability over the season and over the years (interannual variation). The interannual variability of NDVI values, as calculated using coefficient of variation of maximum NDVI, indicate unstable and unpredictable environments. Consequently, high values of coefficient of variation of maximum NDVI relate to areas with variable climate over a number of years and hence low mammal (herbivore) species richness. On the other hand, high values of interannual maximum NDVI indicate stable and predictable environments and hence relate positively with mammal (herbivore) species richness [25]. Many studies have also demonstrated that maximum NDVI has positive linear relationships with species richness of birds and plants $[26,27]$.

Ecologists recognize three levels of diversity: alpha diversity is a measure of richness within a single homogeneous community; beta diversity measures the change in composition along environmental gradients between communities within a landscape; and gamma diversity describes the number of species in a landscape containing more than one community type [4]. Since most management decisions concerning the conservation of species richness in Kenya are made at landscape and regional scales, it is essential to examine gamma diversity and epsilon (regional) diversity. The aim of this paper is to identify the biophysical factors determining mammal species richness at landscape and regional scales in Kenyan rangelands.

\section{MATERIAL AND METHODS}

\section{Study Area and Animal Species Data}

Kenya is situated between latitudes $5^{\circ} 40^{\prime}$ north and $4^{\circ} 4^{\prime}$ south and between longitudes $33^{\circ} 50^{\prime}$ and $41^{\circ} 45^{\prime}$ east (Fig. 1). The study area encompasses 19 rangeland districts of Kenya with diverse landforms ranging from highland moors to savanna grasslands to coastal plains, and the analyses were carried out on individual district, as well as on the combined regional data. The herbivore species (body weight greater than $10 \mathrm{~kg}$ ) data were obtained from Department of Resource Surveys and Remote Sensing (DRSRS), Ministry of Environment and Mineral Resources, Kenya. The systematic reconnaissance flight methodology used by DRSRS for aerial census of animals is well-documented [28]. Statistical analyses to validate DRSRS survey methodology have proved the method and data to be reliable [29, 30]. Topographic maps of scale 1: 250, 000 were used for flight planning and all transects conform to the Universal Transverse Mercator (UTM) coordinate system. The aerial surveys were carried out along transects oriented in east-west direction and spaced at $5 \mathrm{~km}$ intervals. The standard flying height and aircraft speed were $120 \mathrm{~m}$ and $190 \mathrm{~km} / \mathrm{hr}$ respectively. Two experienced and well-trained observers occupied the rear seats of a high wing aircraft (Cessna 185 or Partenevia) and counted animals that appeared between two rods attached to the wing struts. The field of vision between these rods was calibrated by flying repeatedly across ground markers of known spacing [31]. The number of animals falling within the survey strips on either side of the aircraft along each 5 $\mathrm{km}$ transect segment were counted and recorded into tape recorders by the two rear seat observers. Groups of animals more than ten in number were also photographed. After every survey the tape-recorded observations were transcribed to data sheets, which together with processed photographs, were interpreted for mammal species using $10 \times$ binocular microscope and overhead projector.

The study was executed at both landscape and regional scales. In case of the latter, the sample units 5 by $5 \mathrm{~km}$ for species data for each of the 19 districts with at least four years of survey (Fig. 1) were summed over the whole area of every district to give a value for total species richness. Whereas at landscape scale the processed data at a 5 by $5 \mathrm{~km}$ spatial resolution for the districts (Baringo, Kwale, Laikipia, Narok and Samburu) were converted to 10 by $10 \mathrm{~km}$ grid cells by averaging. The number of large mammal species was counted in every grid cell (10 by $10 \mathrm{~km})$ to give a value for total species richness.

\section{AVHRR- NDVI Time Series Data}

AVHRR-NDVI was derived from data collected by the National Oceanic and Atmospheric Administration (NOAA) 
satellites, and processed by the Global Inventory Monitoring and Modeling Studies (GIMMS) at the National Aeronautics and Space Administration (NASA). The GIMMS group developed the GIMMS NDVI first generation dataset [32]. A complete record for Africa exists since August 1981 at 7.6 $\mathrm{km}$ resampled resolution [33]. NDVI is a ratio derived by dividing the difference between near-infrared and red reflectance measurements by their sum:

$N D V I=(N I R-R) /(N I R+R)$

where $N I R=$ near-infrared measurements and $R=$ visible red measurements. Normalization reduces differences due to overall brightness of sunlight or of surfaces (e.g., shadows) that can strongly influence the image. The magnitude of NDVI is related to the level of photosynthetic activity in the observed vegetation [34]. Generally, higher positive values of NDVI indicate vigor and quantity of vegetation [35] whereas negative values are usually associated with bare soil, snow, clouds or non-vegetated surfaces.

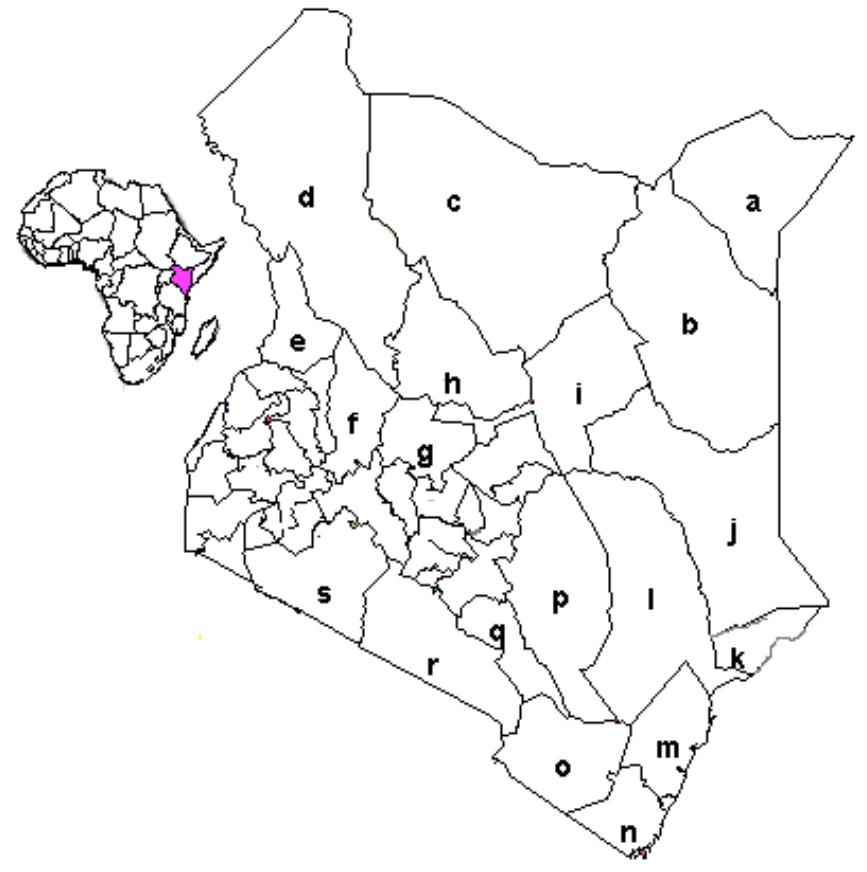

Fig. (1). Location of Kenya and study districts, a-Mandera, b-Wajir, c-Marsabit, d-Turkana, e-West Pokot, f-Baringo, g-Laikipia, hSamburu, i-Isiolo, j-Garissa, k-Lamu, 1-Tana River, m-Kilifi, nKwale, o-Taita Taveta, p-Kitui, q-Machakos, r-Kajiado and sNarok.

Cloud contamination and other atmospheric effects, along with some effects of sensor geometry, attenuate the value of NDVI and contribute to a greater error in the signal. To minimize the effect of cloud and atmospheric contamination, dekadal (10 days) temporal composites of NDVI are developed by choosing the maximum NDVI value for each individual pixel location. The 10-day maximum value composite procedure selects the 'greenest' value [36], which generally represents the least cloud contaminated pixel for each dekad period [32].

When vegetation cover is low, the spectrum observed by remote sensing is generally dominated by soil. Differences of bare soil reflectance may cause large NDVI variations. This results from differences in colour and brightness arising from soil properties as iron amount and organic matter amount [24]. Since Kenya experiences a bimodal rainfall distribution with peaks in April and November, it has two growing seasons. The interannual maximum NDVI used in this study generally represents NDVI at the height of the growing seasons [36]. Moreover, differences in soil reflectance were presumed to cause minor variations of NDVI values because time series data were analyzed for the same pixel area. Thus, the effect of soil background is minimized by using annual time series data as well as the fact that vegetation cover is present and adequate (on an annual basis) across the study area.

\section{Analyses of Data}

The study aims at measuring ecological variations within pixels in such a way that regions affected by occasional droughts or erratic changes in the timing and strength of rains, could be separated from those where the impact of such anomalies is slight. Since the total species richness of a region may be constrained by distinct dry or cold seasons [37], it is important to quantify the anomalous events such as droughts or interannual differences in the timing and strength of rains. This was done by aggregating dekads to their appropriate months, calculating standard deviation of maximum NDVI for each month over the 11 year period, and then averaged the standard deviations for all 12 monthly NDVI values over the 11 year period (same for average NDVI). Thus, the variability over an 11-year period (1982 to 1993) of monthly NDVI values represents temporal variation of productivity. The historical image products of Kenya comprising 396 dekads of maximum NDVI were downloaded from the website [35]. These historical NDVI products are statistical summaries (i.e., average or maximum NDVI) for the historical time period (1982-1993) and hence there is no significant influence from cloud contamination. Since dekads span from the 1st to the 10th, the 11 th to the 20th, and the 21 st to month end, a year has 36 dekads (i.e., 3 dekads multiplied by 12 months). Hence, 396 dekads (i.e., 36 dekads multiplied by 11 years) correspond to an 11-year time period. This implies that each month over an 11-year period has 33 dekads (i.e., 3 dekads multiplied by 11 years). By using Windisp 3.5 time series data processor [38], average NDVI (AV) was computed for each of the 12 months over 11-year period as:

$\mathrm{AV}=1 / \mathrm{n} \Sigma(\mathrm{pv})$

where $p$ is the individual pixel values (i.e., for all 33 dekads maximum NDVI images) and $n$ is the number of dekads. Estimating the average NDVI for all 12 monthly values over 11-year period produced the interannual average NDVI image (Fig. 2a). The standard deviation of NDVI (SD) was also calculated for each of the 12 months over 11-year period as:

$\mathrm{SD}=\sqrt{ }\left(1 / 1-\mathrm{n} \Sigma\left(\mathrm{x}_{\mathrm{i}}-\mathrm{x}\right)^{2}\right)$

where $n$ is the number of observations (i.e., 33 dekads), $\boldsymbol{x}_{\boldsymbol{i}}$ is the deviations from the average and $\mathrm{x}$ is the average NDVI for individual pixels. Calculating the standard deviation for all 12 monthly NDVI values over 11-year period produced the standard deviation of NDVI image (Fig. 2b). Coefficient of variation was calculated by dividing the monthly standard deviation of NDVI with the monthly average NDVI expressed as a percentage. In addition, the average coefficient 
of variation was computed from all 12 monthly values over 11-year period.

At landscape scale, in Narok district mammal species richness and habitat diversity index were estimated in quadrat size of $10 \times 10 \mathrm{~km}$ [17]. The Landsat TM based habitat diversity index was calculated for every sample unit based on habitat map of fine spatial scale (pixel size $=25 \mathrm{~m}$ ) [17] and the commonly used Shannon-Wiener index for quantifying landscape structure was employed [39]. Regression lines between the dependent variables (species richness) and the independent variables (Shannon habitat diversity index) were calculated along with $95 \%$ confidence interval.

Additionally, the coordinates of the sample units for the districts Baringo, Kwale, Laikipia, Narok and Samburu containing species were geometrically conformed to the same geographic coordinate system as the NDVI images. Since the spatial resolution of the species data $(10 \times 10 \mathrm{~km})$ was different from NDVI data $(7.6 \times 7.6 \mathrm{~km})$, the point maps representing species data were overlaid on the NDVI raster images. For every grid cell of $10 \times 10 \mathrm{~km}$ of species data overlaid on the maximum average NDVI and standard deviation of maximum NDVI images, the mean values of average NDVI as well as standard deviation were computed. The interannualy integrated maximum NDVI variables (viz. average NDVI and standard deviation) were extracted using lower left corner coordinates of the sample unit. Thus each sample unit finally contained three variables-NDVI variables (average and standard deviation) and species richness. Regression lines between the dependent variables (species richness) and the independent variables (NDVI variables) were calculated, as well as the $95 \%$ confidence interval.

In the case of regional scale, the entire population of grid cells $(10 \times 10 \mathrm{~km})$ in districts Baringo, Kwale, Laikipia, Narok and Samburu were analyzed as a lumped data set. Moreover, the mean values of interannual average NDVI and coefficient of variation of NDVI were estimated over the whole area of each district. The sample units of 5 by $5 \mathrm{~km}$ for mammal species data for every district were summed over the whole district to give a value for total species richness, only complementary species were considered. Thus, each sample unit (i.e., whole district) finally contained: interannual average NDVI, coefficient of variation of NDVI and species richness. Since, correlation coefficients calculated on a grid-cell by grid-cell (i.e., sample unit by sample unit) basis are often biased by spatial autocorrelation [40], sample of grid cells $(10 \times 10 \mathrm{~km})$ with the highest number of species in every district were selected for the correlation analysis, rather than the entire population [25].

The mean values of interannual average NDVI and coefficient of variation of NDVI were computed over $10 \times 10$ $\mathrm{km}^{2}$ grid cells containing species richness for every district. Regression lines between the dependent variable (species richness) and the independent variables (interannual average NDVI and coefficient of variation of NDVI) were calculated, as well as the $95 \%$ confidence interval.

\section{RESULTS}

The interannual average NDVI exhibits a distinct pattern in Kenya (Fig. 2a). Predictably, the semi-humid to humid zones such as the Lake Victoria region, central highlands and (a)

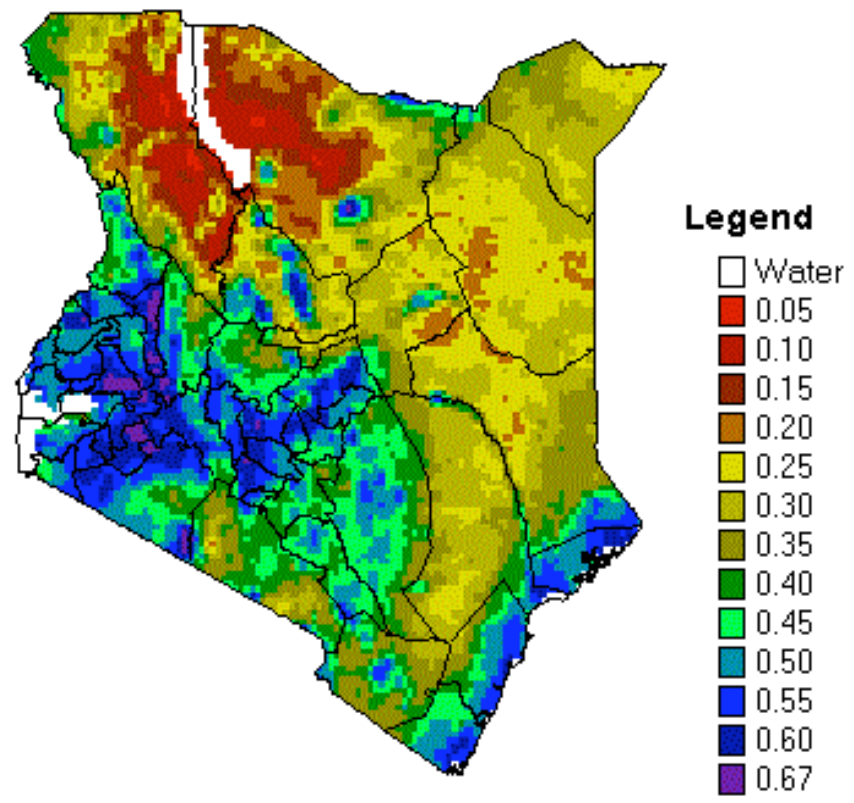

(b)



Fig. (2). Spatial distribution of interannual (1982-1993) maximum NDVI variables in Kenyan rangeland districts: (a) Average NDVI image, (b) Standard deviation image.

the coastal strip have the highest maximum average NDVI. In arid and semi-arid zones, very low values $(<0.05)$ of interannual average NDVI are expected. However, since historical NDVI values are statistical summaries [35], the averaging procedure resulted in the minimum NDVI value of 0.05 . The standard deviation of maximum NDVI (Fig. 2b) also shows regional patterns. High values occur in arid and semiarid zones where large environmental gradients are present within a region, as for example from the northeast to the southeast of Kenya (excluding the coastal strip). Very arid areas (e.g., the northwest around Lake Turkana) exhibit low values, consistent with low average NDVI values. Since the higher the value of NDVI the more photosynthetically active 
the cover type [41], low average NDVI values indicate that these areas have less photosynthetically active cover types.

At landscape scale, the relationships between interannual average NDVI and mammal species richness form parabola or 'hump-shaped' [13] curves in Narok district (Fig. 3a). This indicates that the highest net primary productivity results in lower mammal species richness $(7,8)$. However, when the sample of grid cell $(10 \times 10 \mathrm{~km})$ with the highest number of species in every district was selected for the correlation analysis, rather than the entire population [25], the relation between interannual average NDVI and mammal species richness becomes a positive straight line (Fig. 4a).

To understand the relationship between ecosystem productivity and mammal species richness at regional scale the districts data for Baringo, Kwale, Laikipia, Narok and Samburu were combined (entire population of $10 \times 10 \mathrm{~km}$ sample units) and analyzed concurrently [12]. A unimodal pattern between ecosystem productivity and mammal species richness emerged (Fig. 3b). In addition, the relationship between species richness and interannual average NDVI was examined at regional scale when sample units were whole districts with unequal sizes [25]. Fig. (4b) shows that species richness increases with the increase of interannual average NDVI values, no parabola curve formed.

Environmental heterogeneity indicates that ecosystem productivity varies over an area [15]. Thus the variability in productivity, as defined by standard deviation of maximum NDVI, correlated positively with species richness at regional scale (Fig.5a). In addition, mammal species richness increases with increase in habitat diversity at landscape scale (Fig. 5b). Areas with high coefficient of variation of NDVI have higher mammal species richness (Fig. 6a). However, when selected grid cell of $10 \times 10 \mathrm{~km}$ in every district was combined and analyzed, higher coefficient of variation of NDVI results in lower mammal species richness (Fig.7a).

At regional scale, the coefficient of variation of NDVI shows a negative correlation with mammal species richness (Fig. 7b) which is consistent with the findings of other researchers [27]. However, when the entire population of $10 \times$ $10 \mathrm{~km}$ sample units were analyzed in the districts Baringo, Kajiado, Kilifi, Kwale, Laikipia, Lamu, Narok, Samburu and Taita Taveta concurrently, the relation between coefficient of variation of NDVI and mammal species richness becomes positive (Fig. 6b).

\section{DISCUSSION}

The species diversity of natural communities is hypothesized to either increase or decrease monotonically with ecosystem productivity and to be unimodally related to productivity, with maximum diversity occurring at intermediate levels of productivity $[6,42]$. The results demonstrate that mammal species richness is unimodally related to ecosystem productivity at both landscape and regional scales if the equal size sample units $(10 \times 10 \mathrm{~km})$ are analyzed entirely (Fig. 3a, b). Apparently, intermediate levels of average NDVI coincide with environments with intermediate levels of productivity [9], which is assumed to support a greater biomass in an area. In turn, this enables more individual organisms to coexist, and thus more species at abundances that make it possible for them to maintain viable populations, that over time allows an increase in species richness [43]. (a)



(b)

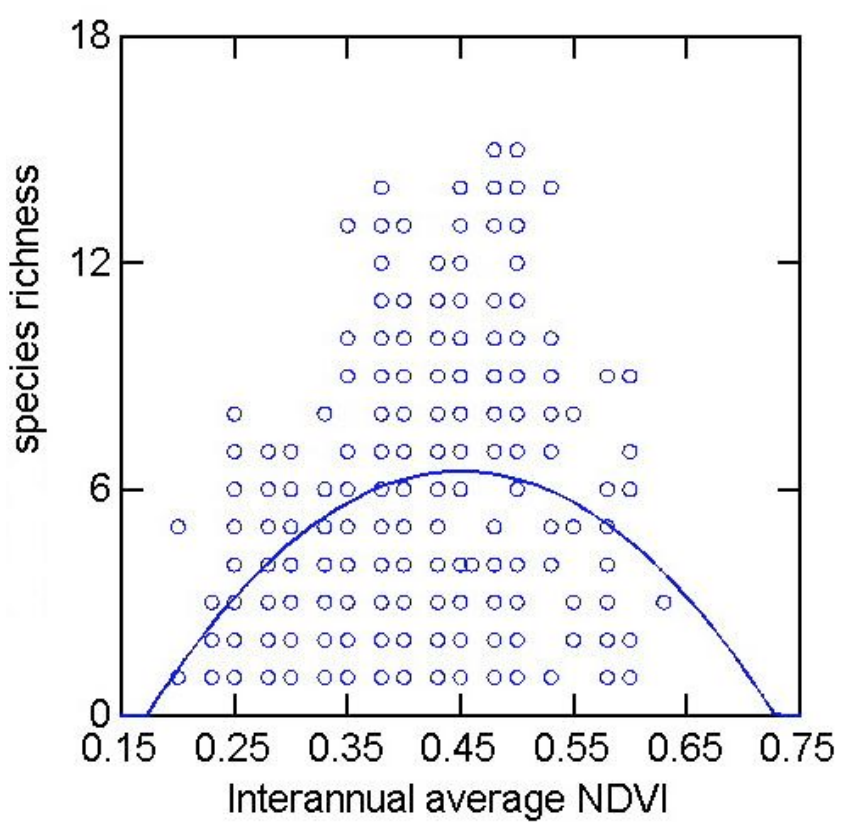

Fig. (3). (a) Quadratic plot of interannual average NDVI versus mammal species richness in Narok district at landscape scale $(r=-$ $0.381, \mathrm{n}=113$ ). (b) Quadratic plot of interannual average NDVI versus mammal species richness at regional scale (entire population of $10 \times 10 \mathrm{~km}$ sample units analyzed) in the districts Samburu, Baringo, Kwale, Laikipia and Narok analyzed as lumped dataset ( $\mathrm{r}$ $=-0.195, \mathrm{n}=378$ ). The relations in $a$ and $b$ are statistically significant at $\mathrm{p}<0.05$.

Moreover, at intermediate levels of productivity, predators (carnivores) can maintain diversity among prey by reducing interspecific competition [15]. This mechanism breaks down in low- and high- productivity environments, where predators are respectively too infrequent to thin their 
(a)

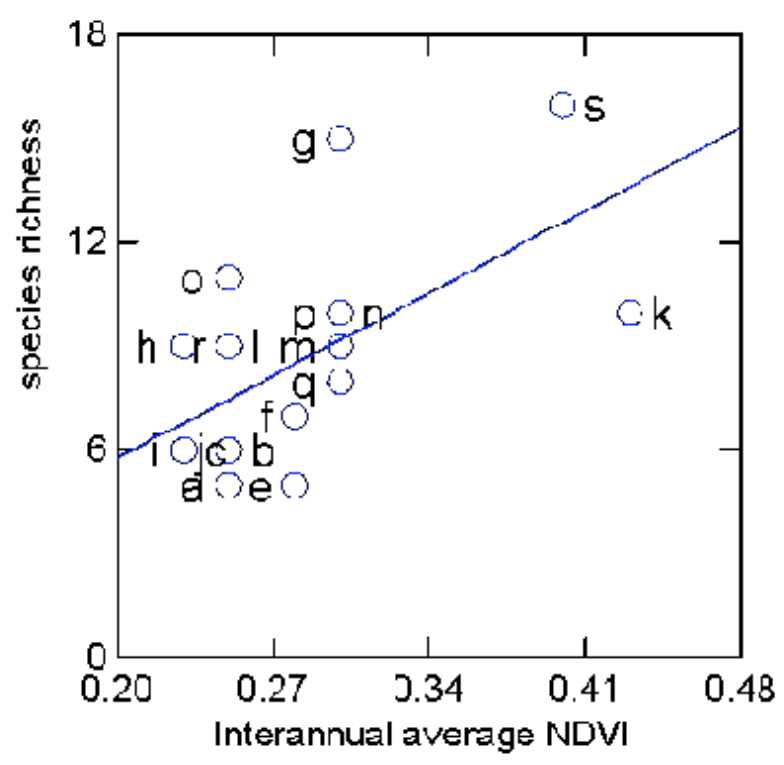

(b)

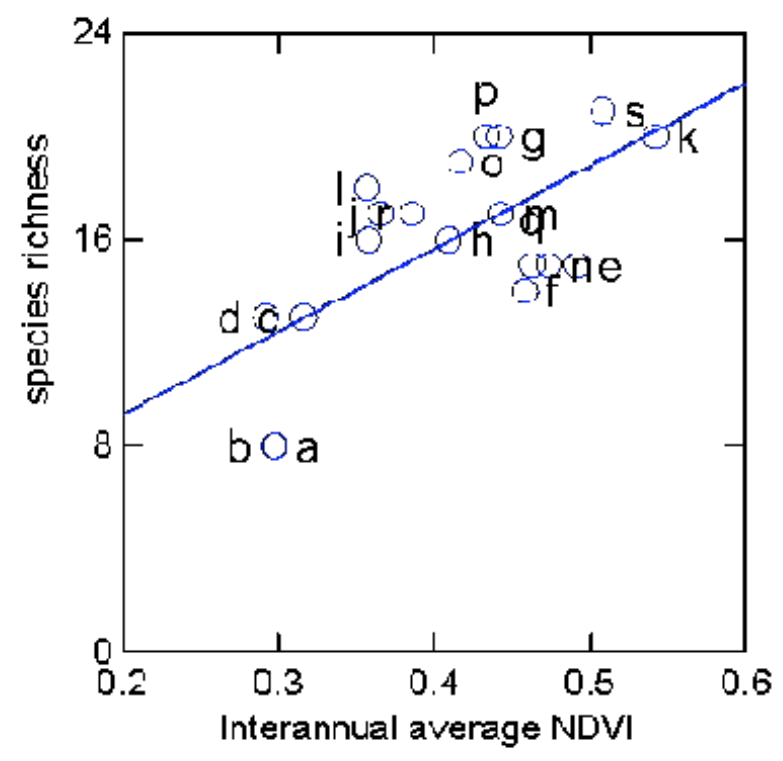

Fig. (4). (a) Scatterplot of interannual average NDVI versus mammal species richness at landscape scale (selected grid cells of $10 \times$ $10 \mathrm{~km}$ analyzed), $\mathrm{r}=0.588, \mathrm{n}=19$. (b) Scatterplots of interannual average NDVI versus mammal species richness at regional scale (sample units, unequal areas of whole districts), $r=0.661, n=19$. The relations in $a$ and $b$ are statistically significant at $p<0.05$. The least-squares fit for the relations in both $\mathrm{a}$ and $\mathrm{b}$ were fitted with straight lines because residuals tend not to vary in a systematic fashion between positive and negative. Symbols for districts are given in Fig. (1).

prey or so numerous that only the best defended prey persist [15]. Furthermore, natural ecosystems with low productivity environments lack niche or resource diversity to allow various species to coexist [4], encouraging species adapted to the more productive niche to dominate the community, thereby (a)



(b)



Fig. (5). Scatterplots of mammal species richness versus (a) standard deviation of maximum NDVI at regional scale $(\mathrm{r}=0.577, \mathrm{n}=$ 113) (b) Shannon habitat diversity index at landscape scale $(r=0$. $725, \mathrm{n}=43$ ). The relations in $a$ and $b$ are statistically significant at $\mathrm{p}<0.05$. The least-squares fit for the relations in both $a$ and $b$ were fitted with straight lines because residuals tend not to vary in a systematic fashion between positive and negative.

decreasing overall species diversity [44]. In higher productivity areas, resource diversity declines due to increased production of woody species, which in turn reduces the primary production of grass resources (because of shading by trees) [45]. Consequently, the reduced variety of resources results in more individuals per few species [46] rather than more species. Although the unimodal patterns suggest that 
(a)



(b)



Fig. (6). (a) Scatterplots of mammal species richness versus coefficient of variation in Samburu district at landscape scale $(r=0.608$, $\mathrm{n}=127$ ). (b) Scatterplots of mammal species richness versus coefficient of variation (entire population of $10 \times 10 \mathrm{~km}$ sample units analyzed) in the districts Baringo, Kajiado, Kilifi, Kwale, Laikipia, Lamu, Narok, Samburu and Taita Taveta analyzed as a lumped data set $(\mathrm{r}=0.222, \mathrm{n}=797)$. The relations in $a$ and $b$ are statistically significant at $\mathrm{p}<0.05$. The least-squares fit for the relations in both $a$ and $b$ were fitted with straight lines because residuals tend not to vary in a systematic fashion between positive and negative.

productivity is a primary factor determining species richness, productivity could simply be correlated with factors that actually generate diversity. One such factor may be environmental heterogeneity [15], in this case estimated from the standard deviation of maximum NDVI (Fig. 5a), coefficient of variation of NDVI (Fig. 6a, b) and habitat diversity index (a)

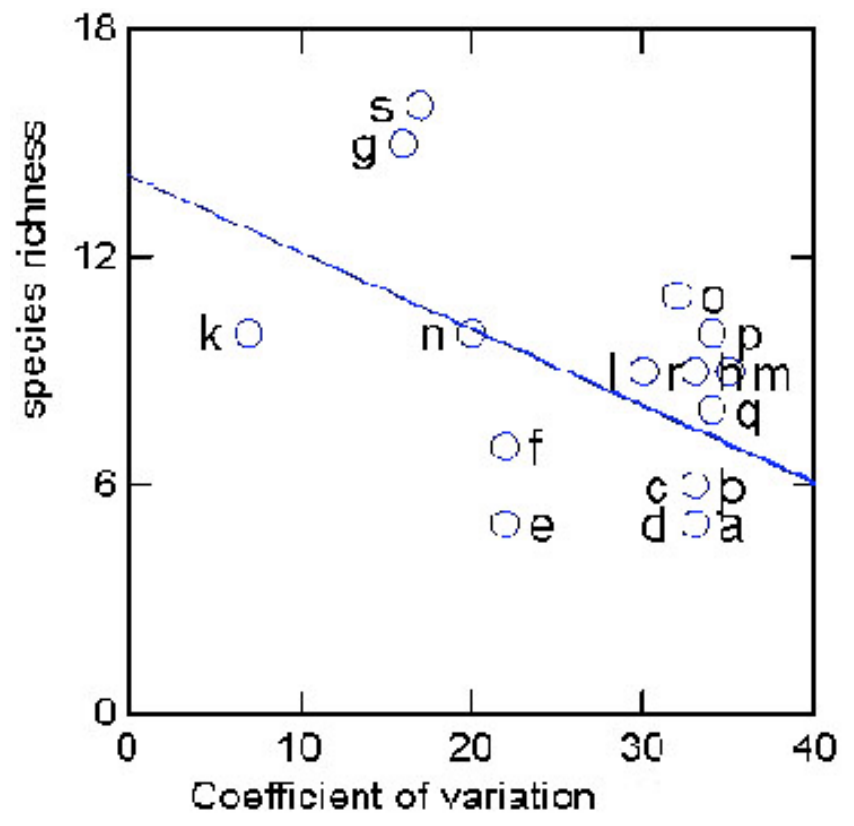

(b)

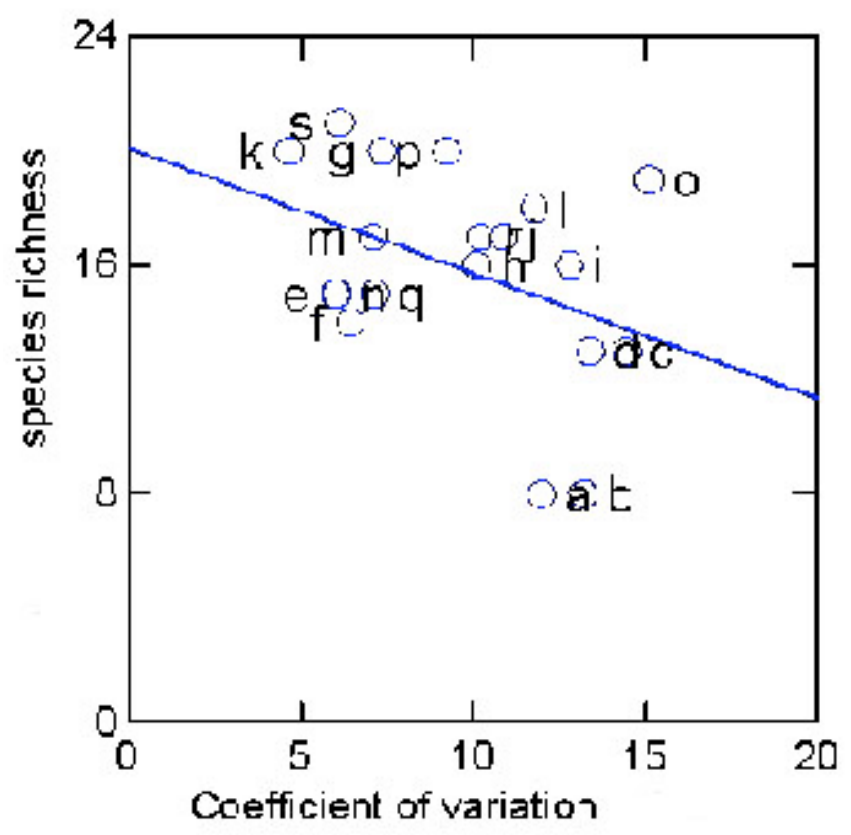

Fig. (7). Scatterplots of coefficient of variation of NDVI versus (a) mammal species richness at landscape scale (selected grid cells of $10 \times 10 \mathrm{~km}$ analyzed), $\mathrm{r}=-0.518, \mathrm{n}=19$ and (b) mammal species richness at regional scale (sample units, unequal areas of whole districts), $\mathrm{r}=-0.495, \mathrm{n}=19$. The relations in $a$ and $b$ are statistically significant at $\mathrm{p}<0.05$. The least-squares fit for the relations in both $a$ and $b$ were fitted with straight lines because residuals tend not to vary in a systematic fashion between positive and negative. Symbols for districts are given in Fig. (1).

estimated from Landsat TM (Fig. 5b). Presumably, variability in maximum NDVI represents spatially heterogeneous environment [47] that reflects diverse habitats and this is in agreement with the findings in Fig. (5b). Since individual species tend to occur only in specific habitats, the number of species increases as habitat diversity increases [48]. Fur- 
thermore, variability in maximum NDVI most likely represents a seasonally changing environment where different species may be suited to conditions at different times of the year. Hence, more numbers of species might be expected to coexist in a seasonal environment than in a completely constant one [46].

However, if the selected (Fig. 4a) sample units $(10 \times 10$ $\mathrm{km}$ ) and whole districts with unequal sizes (Fig. 4b) were analyzed, the relation between mammal species richness and interannual average NDVI is a positive straight line (Fig. 4a, b). In the case of coefficient of variation of NDVI, if the selected (Fig. 7a) sample units $(10 \times 10 \mathrm{~km})$ and whole districts with unequal sizes (Fig. 7b) were analyzed; higher values result in lower mammal species richness. This indicates that under such sampling methods these NDVI variablesinterannual average NDVI and coefficient of variation of NDVI represent climatic variability [25]. The interannual variability in vegetation takes place as a result of climatic variability affecting germination and growth [49]. Hence, large variations in vegetation composition and growth are seen in arid and semi-arid areas where rainfall is sporadic and the response of vegetation to such rainfall is rapid [50]. Thus, the vegetation index time series give us a possibility to assess the climatic variability over the season and over the years [51]. For instance, calculating the coefficient of variation of NDVI for a number of years may describe the relative variability of vegetation cover for a given region. Consequently, regions with high coefficient of variation of NDVI should reflect regions with large variations in vegetation composition and growth. Such regions are likely to have unstable and unpredictable climatic conditions over a number of years. On the other hand, regions with low coefficient of variation of NDVI should depict regions with small variations in vegetation composition and growth. The results (Fig. 4a, b) show that higher interannual average NDVI increases mammal species richness, whereas higher coefficient of variation of NDVI decreases mammal species richness (Fig. 7a, b).

So, why does higher interannual average NDVI favor high species richness? One possible explanation is that interannual average NDVI stands for environmental resources, which may be utilized by herbivores species such as greenleaf biomass, photosynthetically active biomass, and biomass of green vegetation [34, 52, 53]. Interannual average NDVI is strongly associated with climatic variables (average annual rainfall and percentage moisture availability) related to vegetation growth $[25,54]$. Therefore, higher interannual average NDVI should represent high above-ground biomass. Consequently, herbivore species richness should be high in districts with higher interannual average NDVI due to abundance of above-ground biomass [45]. When the coefficient of variation of NDVI over an eleven-year period is considered, districts with highest coefficient of variation have the lowest number of mammal species (Fig. 7a, b). Apparently, regions with high coefficient of variation have high average annual temperature and high potential evapotranspiration [25] that reduce biomass production [55].

Predicting mammal species richness requires precise environmental data. However, the regional perspective requires the sacrifice of ecological precision for the sake of the generality, as well as the provision of more data thereby allow- ing statistical predictions. Environmental and species richness relationships, documented by regression statistics, can be used to identify areas more likely characterized by high species diversity [56]. However, there are limitations inherent to the data and to the approach used. The variability in vegetation cover measured from AVHRR data is the result of multiple influences: interannual variability in rainfall and temperature due to intrinsic characteristics of the climate, climate trends which exceed the 11-year period, vegetation successions, anthropogenic land-cover changes, and variability in the state of the atmosphere [41]. A more comprehensive analysis requires investigation of other characteristics of time variability in surface conditions such as Fourier transform, amplitude of the variations, summed changes between neighboring months, among others [41].

\section{CONCLUSION}

This study has demonstrated that remotely sensed data can provide both spatial and temporal quantitative information on vegetation reflectance, which can be translated into a measure of environmental factors that influence mammal species richness at different spatial scales. At landscape scale, the results established that interannual average NDVI relates to net primary productivity, which increases mammal species richness at intermediate levels of productivity. In addition, standard deviation of maximum NDVI, coefficient of variation of NDVI and Landsat Thematic Mapper derived habitat diversity index relate to habitat heterogeneity, which supports richer assemblages of mammalian species. On the other hand, at regional scale interannual average NDVI reflect stable and predictable environments [51] that support high mammal species richness. This finding is consistent with the hypothesis that high species diversity occurs in stable and predictable environments [21, 22]. It is of particular interest that persistence of stable regional conditions, which permitted species specialization [8], and hence high species diversity, may also have enhanced development of stable human cultures and agricultural development [22]. Hence, the pressure on nature is often particularly great in the districts with high mammalian species richness such as Narok, Laikipia, Taita Taveta and Kitui where numerous cases of human-wildlife conflicts have been reported [57]. The results also demonstrate that coefficient of variation of NDVI represents unstable and unpredictable environments (droughtprone). Such regions have low aboveground biomass that cannot support high mammalian species richness [25]. The study reveals that the multi-temporal data of vegetation reflectance derived from satellites can be used to provide distinction between stable and unstable regions in Kenya.

\section{ACKNOWLEDGEMENTS}

Thanks to Mr. Hesbon. Mwendwa, the then Director of Department Resource Surveys and Remote Sensing (DRSRS) for providing the animal species data. My appreciation goes to the USAID/FEWS project which provided valuable AVHRR NDVI time series images on the Internet.

\section{REFERENCES}

[1] Huston MA. A general hypothesis of species diversity. Am Nat 1979; 113: 81-101.

[2] Pianka ER. Evolutionary ecology. Harper and Row, Publishers, Inc: New York 1983. 
[3] Myers AA, Giller PS, Eds. Analytical Biogeography. An integrated approach to the study of animal and plant distributions. Chapman \& Hall: London 1988

[4] Stoms DM, Estes JE. A remote sensing research agenda for mapping and monitoring biodiversity. Int J Remote Sens 1993; 14: $1839-60$.

[5] Grime JP. Plant strategies and vegetation processes. John Wiley \& Sons: New York 1979.

[6] Ricklefs RE, Schluter D, Eds. Species diversity in ecological communities. Historical and geographical perspectives. University of Chicago Press: Chicago 1993.

[7] Owen JG. Patterns of mammalian species richness in relation to temperature, productivity, and variance in elevation. J Mammal 1990; 71: 1-13.

[8] Currie DJ. Energy and large-scale patterns of animal and plant species richness. Am Nat 1991; 137: 27-49.

[9] Box EO, Holben BN, Kalb V. Accuracy of the AVHRR Vegetation Index as predictor of biomass, primary productivity and net $\mathrm{CO}_{2}$ flux. Vegetatio 1989; 80: 71-89.

[10] Foody GM. Mapping the richness and composition of British breeding birds from coarse spatial resolution satellite sensor imagery. Int J Remote Sens 2005; 26: 3943-56.

[11] Foody GM, Cutler MEJ. Mapping the species richness and composition of tropical forests from remotely sensed data with neural networks. Ecol Model 2006; 195: 37-42.

[12] Oindo BO. Predicting mammal species richness and abundance using multi-temporal NDVI. Phot Eng Remote Sens 2002a; 68: 623-9.

[13] Huston MA. Biological Diversity. The coexistence of species on changing landscapes. Cambridge University Press: Cambridge 1994.

[14] Podolsky R. Ecological hot spots. A method for estimating biodiversity directly from digital Earth imagery. Earth observation magazine 1994; June, pp. 30-6.

[15] Morin PJ. Biodiversity's ups and downs. Nature 2000; 406: 463-4.

[16] O'Neil RV, Krummel JR, Gardener RH, et al. Indices of Landscape Pattern. Landsc Ecol 1988; 1: 153-62.

[17] Woody T, Sacha S, Ned G, Matthew F, Eleanor S, Marc S. Remote sensing for biodiversity science and conservation. Trends Ecol Evol 2003; 18: 306-14.

[18] Oindo BO, Skidmore A, De Salvo P. Mapping habitat and biological diversity in the Maasai Mara ecosystem. Int J Remote Sens 2003; 24: 1053-69.

[19] Oindo BO, Skidmore A. Interannual variability of NDVI and species richness in Kenya. Int J Remote Sens 2002; 23: 285-98.

[20] Bawa K, Rose J, Ganeshaiah KN, Barve N, Kiran MC, Umashaanker R. Assessing biodiversity from space. An example from western Ghats, India. Conserv Biol 2002; Online; http;//www. consecol.org/vol6/iss2/art7/

[21] Sanders HL, Hessler RR. Ecology of the deep sea benthos. Science 1969; 163: 1419-24

[22] Fjeldså J, Lovett JC. Biodiversity and environmental stability. Biodivers Conserv 1997; 6: 315-23.

[23] Henricksen BL. Reflections on drought: Ethiopia 1983-1984. Int J Remote Sens 1986; 7: 1447-51.

[24] Richard Y, Poccard I. A statistical study of NDVI sensitivity to seasonal and interannual rainfall variations in Southern Africa. Int J Remote Sens 1998; 19: 2907-20.

[25] Oindo BO. Patterns of herbivore species richness in Kenya and current ecoclimatic stability. Biodivers Conserv 2002b; 11: 120521.

[26] Bailey SA, Horner-Devine MC, Luck G, et al. Primary productivity and species richness: relationships among functional guilds, residency groups and vagility classes at multiple spatial scales. Ecography 2004: 27: 207-17.

[27] Gillespie TW. Predicting woody-plant species richness in tropical dry forests: case study from south Florida, USA. Ecol Model 2006; 195: 37-42.

[28] Norton-Griffiths M. Counting animals, Handbook no.1. Africa Wildlife Leadership Foundation: Nairobi 1978.

[29] De Leeuw J, Prins HHT, Njuguna EC, Said MY, De By R. Interpretation of DRSRS animal counts (1977-1997) in the rangeland districts of Kenya. Ministry of Planning and National Development: Nairobi 1998.

[30] Ottichilo WK, Khaemba WM. Validation of observer and aircraft calibration for aerial animal surveys: A case study of the Depart- ment of Resource Surveys and Remote Sensing (DRSRS), Kenya. Afr J Ecol 2001; 39: 45-50.

[31] Ottichilo WK, Sinange RK. Differences in the visual and photographic measurements in the estimation of strip widths for aerial censuses of animal populations. DRSRS, Ministry of Planning and National Development: Nairobi 1985.

[32] Holben BN. Characteristics of maximum-value composite images for temporal AVHRR data. Int J Remote Sens 1986; 7: 1417-34.

[33] Los SO. Linkages between Global Vegetation and Climate. An analysis based on NOAA Advanced Very High Resolution Radiometer Data. GSFC/CR- 1998-206852, National Aeronautics and Space Administration, Goddard Space Flight Center, Greenbelt, Maryland 1998.

[34] Tucker CJ, Sellers PJ. Satellite remote sensing of primary production. Int J Remote Sens 1986; 7: 1133-5.

[35] Africa Data Dissemination Service, EROS Data Center, U.S. Geological Survey Sioux Falls, South Dakota, US 57198. $24^{\text {th }}$ February 2000: Available from: http://edcsnw4.cr.sgs.gov/bin/staform/a=ndv $\mathrm{i} / \mathrm{b}=\mathrm{ke}$

[36] Lewis JE, Rowland J, Nadeau A. Estimating maize production in Kenya using NDVI: Some statistical considerations. Int J Remote Sens 1998; 19: 2609-17.

[37] Fjeldså J, Ehrlich D, Lambin E. Are biodiversity 'hospots' correlated with current ecoclimatic stability? A pilot study using the NOAA-AVHRR remote sensing data. Biodivers Conserv 1997; 6 : 401-22.

[38] Pfirman E, Hogue J, See L. Windisp 3.5. Map and image display system version 990217. UN Food and Agriculture Organization, USAID Famine Early Warning System, Southern Africa Development Community, US Forest Service and US Geological Survey 1999.

[39] Haines-Young R, Chopping M. Quantifying landscape structure: a review of landscape indices and their application to forested landscape. Prog Phys Geogr 1996; 20: 418-45.

[40] Odland J. Spatial autocorrelation. Sage University Scientific Geography series 9. Sage publications, Beverly Hills, California, 1988

[41] Sellers PJ. Canopy reflectance, Photosynthesis and transpiration. Int J Remote Sens 1985; 6: 1335.

[42] Tilman D. Resource competition and community structure, Princeton University Press, Princeton: New Jersey 1982.

[43] Gaston KJ. Global patterns in biodiversity. Nature 2000; 405: 2207.

[44] Kassen R, Buckling, A, Bell G, Rainey PB. Diversity peaks at intermediate productivity ina laboratory microcosm. Nature 2000; 406: 508-12.

[45] Newbery DM, Prins HHT, Brown ND, Eds. Dynamics of Tropical Communities. Blackwell Science: Oxford 1998

[46] Begon M, Harper JL, Townsend CR. Ecology: Individuals, populations and Communities, Blackwell Scientific Publications: Oxford 1990.

[47] Walker RE, Stoms DM, Estes JE, Cayocca KD. Proceedings Annual Meeting of ASPRS/ACSM, American Society for Photogrammetry and Remote Sensing, 3-7 March 1992, Albuquerque, New Mexico, Bethesda, MD 1992.

[48] Diamond J. Factors controlling species diversity: Overview and synthesis. Ann Missouri Bot Garden 1988; 75: 117-29.

[49] Hobbs RJ, Mooney HA, Eds. Remote Sensing of Biosphere Functioning. Ecological Studies 79, Springer-Verlag: New York 1990

[50] Griffin GF, Friedal MH. Discontinuous change in central Australia: some major implications of ecological events for land management. J Arid Environ 1985; 9: 63-82.

[51] Oindo BO, de By RA, Skidmore AK. Interannual variability of NDVI and bird species diversity. Int J Appl Earth Obs Geoinfo 2000; $2: 172-80$.

[52] Holben BN, Tucker CJ, Fan CJ. Spectral assessment for soybean leaf area and leaf biomass. Phot Eng Remote Sens 1980; 46: 65156 .

[53] Asrar G. Theory and Applications of Optical Remote Sensing. Wiley Series in Remote Sensing, John Wiley \& Sons: New York 1989.

[54] Nicholson SE, Davenport ML, Malo AR. A comparison of the vegetation response to rainfall in the Sahel and East Africa, using Normalized Difference Vegetation Index from NOAA-AVHRR. Clim Change 1990; 17: 209-42.

[55] Hacker JB, Ternouth JH, Eds. The Nutrition of herbivores. Academic Press Australia: Sydney 1987. 
[56] Miller RI, Stuart SN, Howell KM. A methodology for analyzing rare species distribution patterns utilizing GIS technology: The rare birds of Tanzania. Landsc Ecol 1989; 2: 173-89.
[57]

Aligula HM, Said MY, Njuguna EC, de Leeuw J, Skidmore AK. Proceedings of the International Conference on Geo-Information for sustainable land management, 17-21 August 1997, Enschede, ITC, The Netherlands 1997.

Received: September 17, 2008

Revised: October 30, 2008

Accepted: October 31, 2008

(C) Boniface Oluoch Oindo; Licensee Bentham Open

This is an open access article licensed under the terms of the Creative Commons Attribution Non-Commercial License (http: //creativecommons.org/licenses/by$\mathrm{nc} / 3.0 /$ ) which permits unrestricted, non-commercial use, distribution and reproduction in any medium, provided the work is properly cited. 